\title{
Immunoreactivity of Vacuolar $\mathrm{H}^{+}$-ATPase in Human Tissues -Using Polyclonal Rabbit Antibodies against V-ATPase Subunits
}

\author{
Shuxin Hu' ${ }^{1}$, Hisayoshi Inoue ${ }^{2}$, Yoshinori Moriyama ${ }^{3}$, Kunihiko Goto ${ }^{1}$ \\ and Takashi Sawai ${ }^{4}$ \\ 'Department of Pathology, Tohoku University Hospital, Sendai 980-77, ${ }^{2}$ Department of Orthopaedics, Tohoku Rosai \\ Hospital, Sendai 980, ${ }^{3}$ Marine Biological Laboratory, Graduate Department of Gene Science, Faculty of \\ Sciences, Hiroshima University, Mukaishima, Hiroshima 722 and ${ }^{4}$ The First Department of Pathology, \\ Iwate Medical University, Morioka 020-8505
}

Received for publication February 7, 1998 and in revised form April 20, 1998 and re-revised form June 19, 1998

\begin{abstract}
We immunohistochemically examined tissue distribution and cellular localization of vacuolar $\mathrm{H}^{+}$-ATPase (V-ATPase), which is a proton-translocating ATPase known as an acidifier of cytoplasmic vesicles and vacuoles, using two polyclonal rabbit antibodies against $A$ and $B$ subunits of the V-ATPase purified from bovine chromaffin granules. The intense staining was found in epithelial cells of the renal tubules and the salivary ducts, pancreatic $\alpha$ cells, endocrine cells in colon, macrophages, osteoclasts, and chondrocytes in human tissues, and the following three localization patterns of V-ATPase were found in the examined cells: 1) cytoplasmic pattern with granular and diffuse types, 2)
\end{abstract}

polarized pattern, and 3) diffuse apical cytoplasm pattern. The granular type of cytoplasmic pattern was typically observed with high density in macrophages, $\alpha$ cells of the pancreatic islets and endocrine cells in colon. The diffuse type was often seen in most of ductal cells of exocrine glands, osteoclasts, nerve cells with moderate density, and in chondrocytes with high density, and the polarized pattern was represented by intercalated cells of the renal tubules with high density. The diffuse apical cytoplasm pattern was typically found along the brush border of proximal tubules from moderate to high density.

Key words: V-ATPase, Human tissues, Immunohistochemistry

\section{Introduction}

V-ATPase is a proton-translocating ATPase known as an acidifier of cytoplasmic vesicles and vacuoles. VATPase consists of multimeric complexes with cytoplasmic V1 and membrane-bound V0 domains. Cytoplasmic ATP is hydrolyzed in the V1 domain, forcing protons away from the cytoplasm through the VO domain and across the membrane. The V1 domain, containing the ATP catalytic site, is composed of a hexamer of three subunit A (65-77 kDa) and three subunit $B(55-60 \mathrm{kDa})$ proteins plus accessory subunit $C(40-45 \mathrm{kDa}), \mathrm{D}(33-$ $34 \mathrm{kDa}$ ) and $\mathrm{E}(26-33 \mathrm{kDa})$. The $\mathrm{V} 0$ domain, as a proton transporter, is composed of four subunits of $16 \mathrm{kDa}$, one subunit of $20 \mathrm{kDa}$ and one subunit of $115 \mathrm{kDa}$. Multiple isoforms have so far been found for each of subunit A, B,

Correspondence to: Shuxin Hu, MD, Department of Pathology, Tohoku University Hospital, 1-1 Seiryo-machi, Aoba-ku, Sendai 980-77, Japan. and $\mathrm{E}[5,17,26,32,33]$.

V-ATPase is highly conserved at the protein level throughout evolution from archaebacteria to mammals. V-ATPase mainly exists in the intracellular vesicles such as lysosomes, endosomes, secretory granules, and Golgi apparatus where it acidifies the intravesicular environment. This is necessary for keeping proteinases active to digest the intracellularly engulfed materials, and helping to transport the synthesized proteins to their destination. VATPase is also found on the plasma membrane of some cells such as the ruffled border of the osteoclasts and the plasma membrane of the renal tubular epithelial cells, where V-ATPase extrudes proton actively from blood to urine, to maintain the systemic acid-base balance $[5,17$, $26,32,33$. Recently, the roles of V-ATPase have been noted in the apoptosis of cells, metastasis of some tumors, as well as in the infective pathways of virus [15, 25, 34]. These discoveries show a prospective feature in clinical application.

In humans, the V-ATPase protein has been found in 
brain [2], kidney [18], and osteoclasts [39]. Hille [19] reported mRNAs of subunits of $A, C, D$, and $E$ existed in many organs including kidney, liver and pancreas using the probe developed from human osteoclastoma. Their distribution, however, in human tissues has not been studied systemically. Since there is a disagreement, for example, about whether the V-ATPase that exists in the plasma membrane of renal tubules is the same protein that exists in the ruffled border of osteoclasts [12], knowledge about the tissue distribution and cellular localization of the V-ATPase protein in human tissues is necessary to understand the V-ATPase function in vivo. In this study, we examined the expression of the subunit A of V-ATPase immunohistochemically using the antibody against that from bovine chromaffin granules. This subunit is known as the most preserved one among all of the 11 subunits in evolution. In addition, this is the most basic and functions in conjunction with subunit $B$ as a catalytic unit [26]. Considering the variety of cell and tissue localization of subunit $A$, we also investigated the distribution of subunit $B$.

The significance of V-ATPase in osteoclasts has supposedly been to acidify the extracellular lacunae between osteoclasts and bone surface, and to activate lysosomal enzymes such as cathepsins $[9,14]$, while carbonic anhydrase II (CA II) is known to be a producer of protons by $\mathrm{CO}_{2}$ hydration [18]. In order to clarify whether these proteins are synthesized by the same cells, we further observed the mutual relationship among the localization of V-ATPase, carbonic anhydrase II (CA II) and cathepsin D using relevant antibodies.

\section{Materials and Methods}

\section{Tissue samples}

Human tissues, including lung, kidney, salivary gland, pancreas, esophagus, stomach, colon, adrenal gland, thyroid gland, brain, bone and lymph node were taken from 5 autopsy cases within $2.5 \mathrm{hr}$ after death. The tissues of the above five cases used in this study showed no remarkable pathological changes. Normal tissues of kidney and salivary gland from surgical specimens were selected in order to understand the changes of immunostaining after death (Table 1).

\section{Fixation and section preparation}

All tissues taken from autopsy and surgery were prepared for paraffin sections. In order to confirm the results obtained from paraffin sections, cryosections were made from parts of tissues including kidney and salivary gland. For paraffin sections, tissues were fixed in $4 \%$ paraformaldehyde in phosphate-buffered saline (PFA-PBS) for $2 \mathrm{hr}$, embedded in paraffin and sectioned at a thickness of $2 \mu \mathrm{m}$. They were stored at $4^{\circ} \mathrm{C}$ until staining. Bone samples were decalcified in EDTA for $48-72 \mathrm{hr}$, but otherwise they were processed as done in non-decalcifying tissues. For cryosections, tissues were fixed in paraformaldehyde-
Table 1. Five cases of autopsy and four surgical specimens

\begin{tabular}{|c|c|c|c|c|c|c|}
\hline \multicolumn{7}{|c|}{ cases of autopsy } \\
\hline No & Age & Sex & \multicolumn{2}{|c|}{ Postmortem time } & \multicolumn{2}{|r|}{ Cause of death } \\
\hline 1 & 72 & $\mathbf{M}$ & \multicolumn{2}{|c|}{$1.0 \mathrm{hr}$} & \multicolumn{2}{|c|}{ Acute myocardial infarction } \\
\hline 2 & 34 & $\mathrm{~F}$ & \multicolumn{2}{|c|}{$1.0 \mathrm{hr}$} & \multicolumn{2}{|c|}{ Hypertrophic cardiomyopathy } \\
\hline 3 & 70 & $\mathbf{M}$ & \multicolumn{2}{|c|}{$1.5 \mathrm{hr}$} & \multicolumn{2}{|c|}{ Acute myocardial infarction } \\
\hline 4 & 59 & $\mathbf{M}$ & \multicolumn{2}{|c|}{$2.5 \mathrm{hr}$} & \multicolumn{2}{|c|}{ Myocardial infarction } \\
\hline 5 & 61 & $\mathbf{F}$ & \multicolumn{2}{|c|}{$1.5 \mathrm{hr}$} & \multicolumn{2}{|c|}{ Acute interstitial pneumonia } \\
\hline \multicolumn{7}{|c|}{ surgical specimens } \\
\hline & & & No & Age & Sex & Clinical diagnosis \\
\hline \multicolumn{7}{|c|}{ Kidney } \\
\hline & & & 1 & 73 & $\mathbf{M}$ & Renal cell carcinoma \\
\hline & & & 2 & 74 & $\mathbf{F}$ & Renal cell carcinoma \\
\hline \multicolumn{7}{|c|}{ Salivary gland } \\
\hline & & & 1 & 69 & $\mathbf{M}$ & Epithelioid granuloma \\
\hline & & & 2 & 61 & $\mathbf{M}$ & Adenocarcinoma \\
\hline
\end{tabular}

lysine-periodate (PLP) for $5 \mathrm{hr}$ at $4^{\circ} \mathrm{C}$, immersed in gradient sucrose serials $(10 \%$ for $6 \mathrm{hr}, 15 \%$ for $6 \mathrm{hr}$ and $20 \%$ for $12 \mathrm{hr}$ ) at $4^{\circ} \mathrm{C}$, then frozen quickly in dry iceacetone, sectioned into $4 \mu \mathrm{m}$, dried for $30 \mathrm{~min}$, and stored at $-20^{\circ} \mathrm{C}$ until staining.

For Western blot analysis, tissues were frozen immediately after sampling, and stored at $-70^{\circ} \mathrm{C}$ until use.

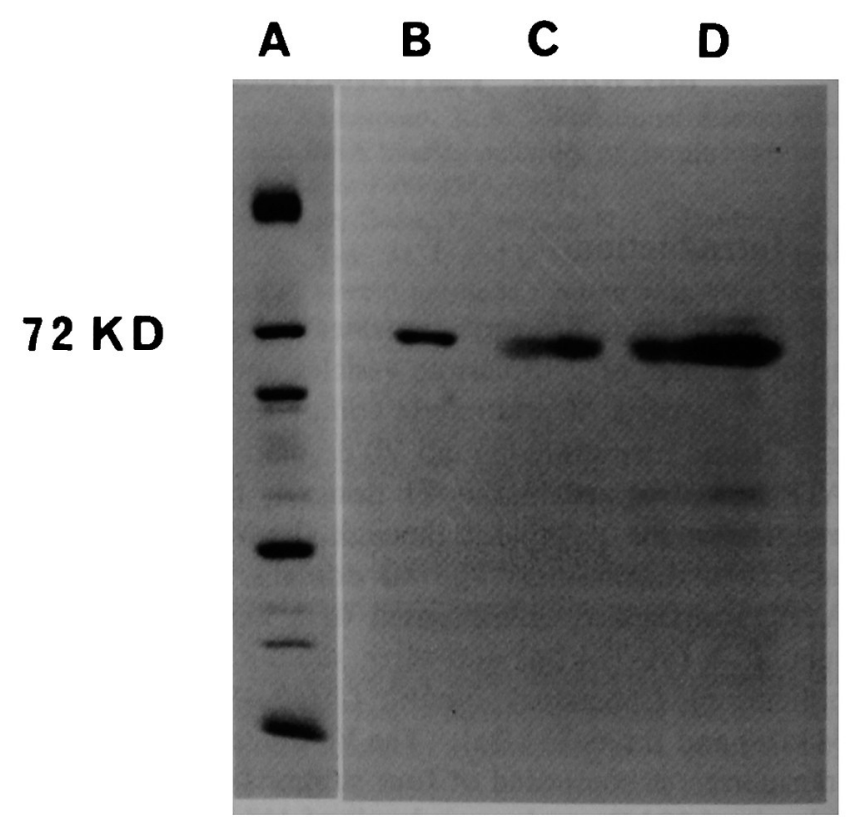

Fig. 1. Immunoblotting analysis of the cross reactivity of the antibody against the subunit $\mathrm{A}$ of V-ATPase in human salivary gland (lane C) and kidney (lane D). Subunit A (72 kDa) of V-ATPase purified from bovine chromaffin granules is also loaded (lane B). Purified V1 of V-ATPase from bovine chromaffin granules is electrophoresed and stained with Coomassie Brilliant Blue (lane A). 


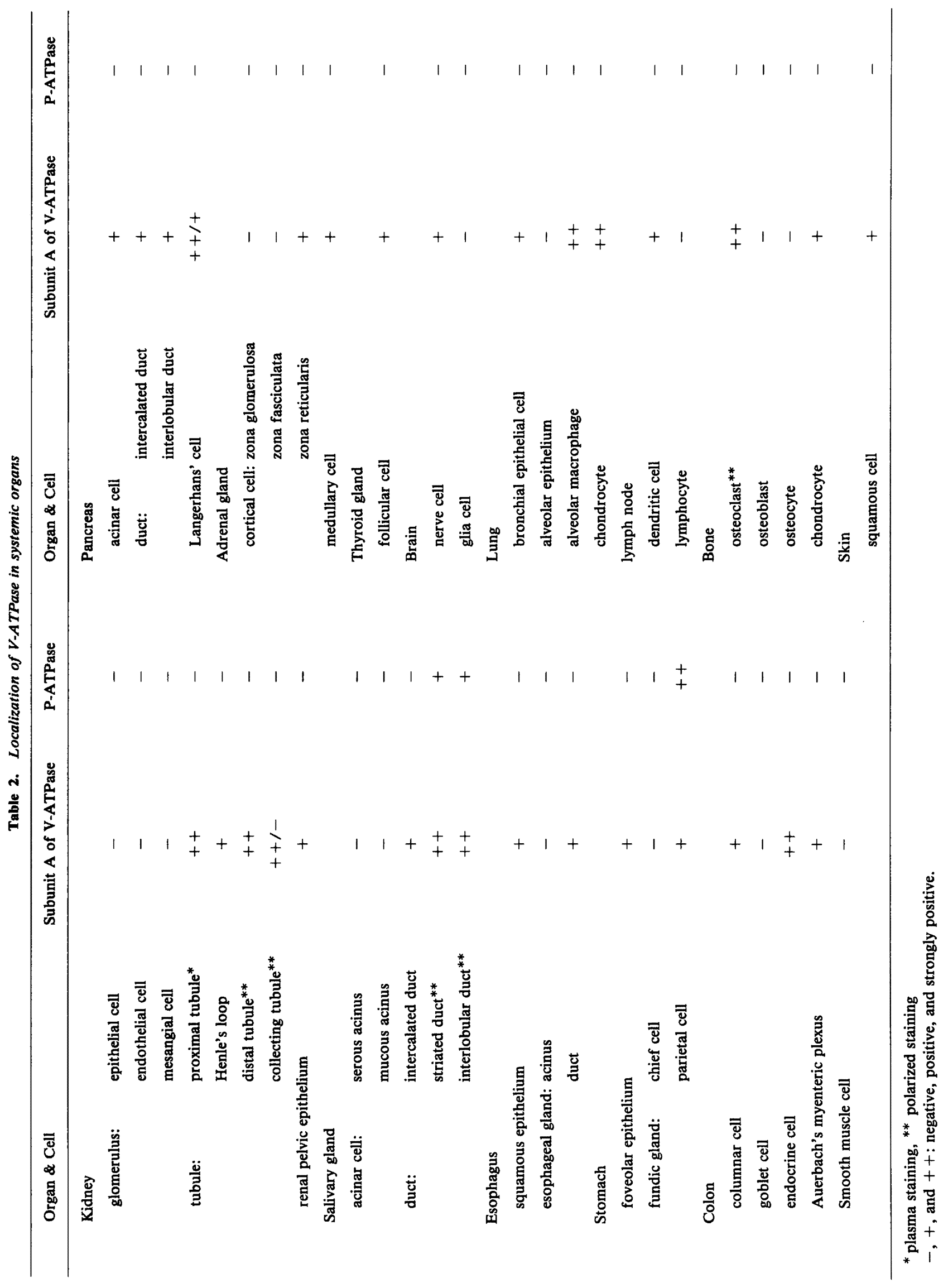




\section{Antibodies and the cross reactivity}

Polyclonal antibodies against subunits A and B of VATPase were prepared as reported previously $[27,28]$. The cross reactivity of the antibody against subunit $\mathrm{A}$ was confirmed by the immunoblotting analysis using fresh tissues from human kidney and salivary gland. In brief, frozen tissues were homogenized in SDS sample buffer (tissues/buffer: 1/20). The protein in the supernatant was separated by electrophoresis on SDS polyacrylamide gel (12\% acrylamide), and electrophoretically transferred to Immobilon-P membranes (Millipore, USA). The antibody against the subunit $\mathrm{A}$ of V-ATPase was diluted to $1: 1000$ and reacted for $2 \mathrm{hr}$ at room temperature. The strip was washed, reacted with the peroxidase-labeled second antibody diluted to $1: 1000$ for $1 \mathrm{hr}$ at room temperature, washed and color was developed as per the manufacturer's instruction (Konica Immunostain HRP$100 \mathrm{Kit}$, Japan). The subunit-72 kDa of V-ATPase purified from bovine chromaffin granules [27] was used as a positive control.
An antibody against P-ATPase of hog stomach was provided by Dr. K. Omori (Kansai Medical University) [40]. Other antibodies used in this study included anti-insulin $\kappa 60$, anti-glucagon and anti-somatostatin monoclonal antibodies (DAKO, Denmark) for $\alpha, \beta$ and $\delta$ islet cells of pancreas; anti-CD68 (DAKO, Denmark) and anti-cytokeratin (COSMO Bio Co, LTD, Japan) monoclonal antibodies to identify V-ATPase-positive cells; anticathepsin D (Novocastra Laboratory, LTD, England) and anti-carbonic anhydrase II (CAII) antibodies (Rockland, USA) to observe the relationship between these two enzymes; and V-ATPase during the resorption of bone. Bound primary antibodies were detected with the goat anti-rabbit IgG secondary antibody (Dako, Japan).

\section{Immunohistochemical staining}

Paraffin sections were deparaffinized with xylene, treated with methanol containing $1 \% \mathrm{H}_{2} \mathrm{O}_{2}$ for $30 \mathrm{~min}$ to block endogenous peroxidase activity, and rinsed in PBS. Sections were first exposed to the blocking solution $(10 \%$

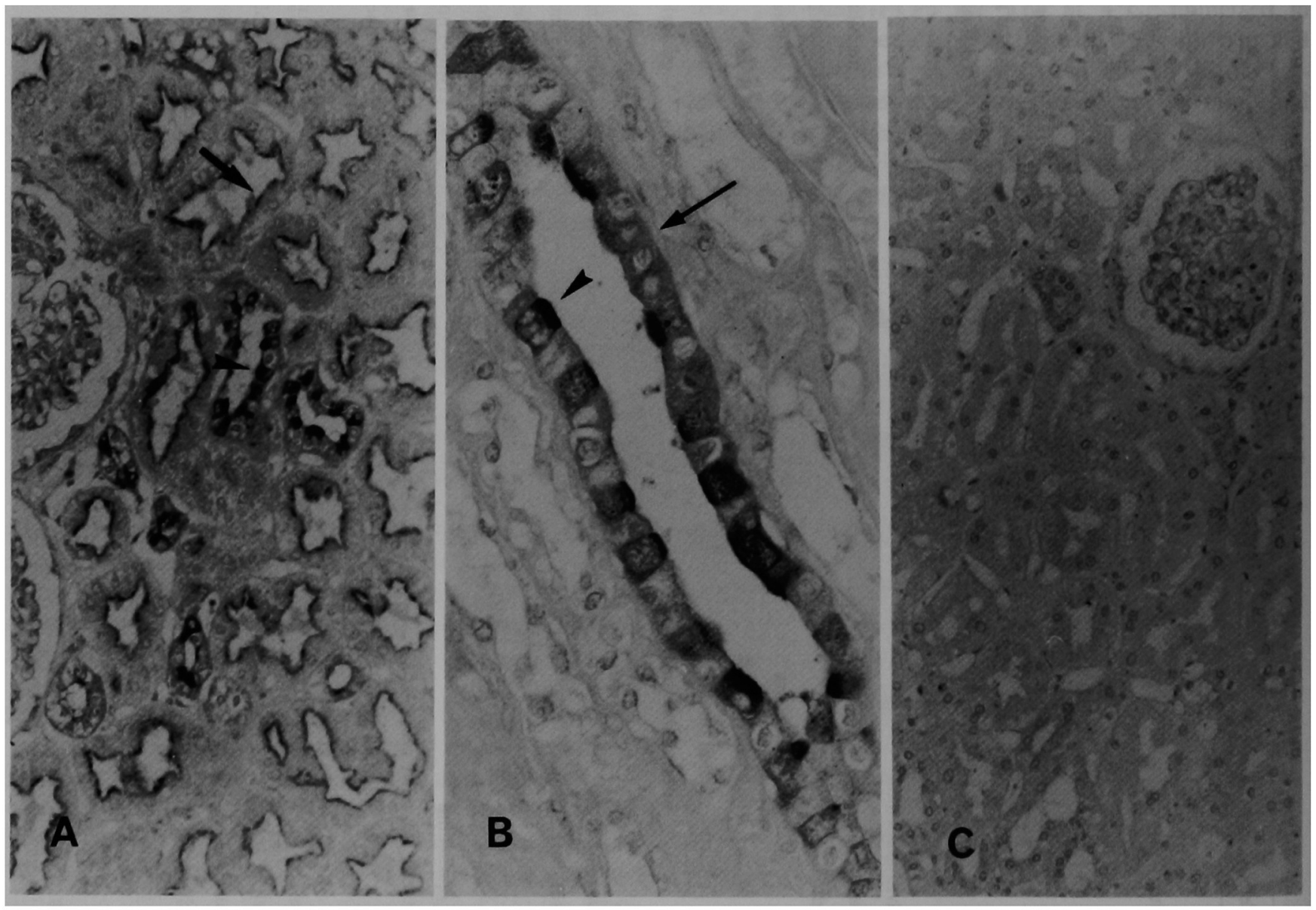

Fig. 2. Immunocytochemical staining of the human kidney with the antibody against the subunit A of V-ATPase. A) All cells of proximal tubules (PT) are moderately positive on the apical plasma membrane (arrow). The intercalated cells (IC, arrowhead) of distal tubules (DT) are intensely stained on the apical plasma membrane and adjacent cytoplasm. All cells from the glomerulus are negative. B) The IC (arrowhead) in the inner medullary collecting tubules (IMCT) demonstrate similar staining patterns as those in DT, and the principal cells (PC, arrow) are weakly positive. C) Immunoreactivity turns negative when sections are reacted with normal serum instead of the primary antibody against V-ATPase. A \& C $\times 50$, B $\times 100$. 
normal goat serum) for $30 \mathrm{~min}$ at room temperature to reduce nonspecific background staining. Sections were then incubated with each primary antibody for $12 \mathrm{hr}$ at $4^{\circ} \mathrm{C}$. Polyclonal antibodies against subunits $A$ and $B$ of V-ATPase were used at a dilution of $1: 1000$ and 1:800 respectively. After washing with PBS (3 times, $5 \mathrm{~min}$ each), sections were incubated for $30 \mathrm{~min}$ with the biotinylated goat anti-rabbit IgG antibody diluted to $1: 50$, rinsed in PBS, and then incubated for $60 \mathrm{~min}$ with avidin-biotin-peroxidase complex $(\mathrm{ABC})$. After washing in PBS, they were reacted with $3^{\prime}-3^{\prime}$ diaminobenzidine tetrahydrochloride (DAB) for $30 \mathrm{~min}$, rinsed in PBS and counterstained with methyl green.

For cryosections, the anti-subunit $\mathrm{A}$ antibody was used at the dilution of $1: 20000$.

\section{Control}

Normal serum as the substitute for the primary anti- bodies was adopted as negative controls. Staining of PATPase serves as a comparative control, and the antibody against P-ATPase was used with a dilution of $1: 1000$.

\section{Evaluation of staining results}

The results of V-ATPase staining were graded as - (negative), + (positive) and ++ (strongly positive) .

\section{Results}

The immunoblotting test with the antibody against VATPase A subunit demonstrated a clear band at the same position of the marker $72 \mathrm{kDa}$ in kidney and salivary gland (Fig. 1).

The results of the V-ATPase immunostaining are summarized in Table 2. Various kinds of cells in human tissues were positive for V-ATPase. The distribution and staining pattern of subunits $A$ and $B$ were substantially the
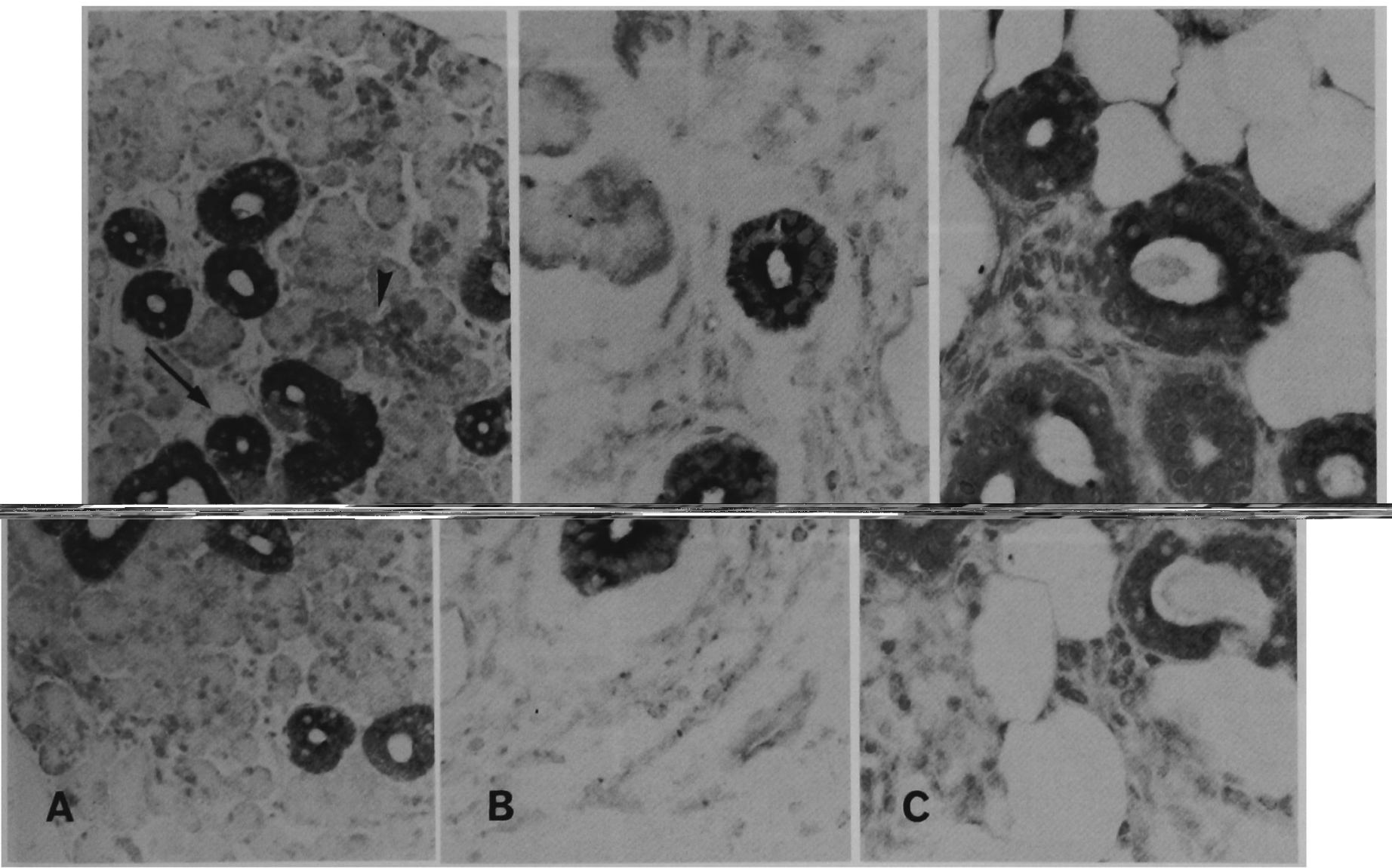

Fig. 3. Striated ducts (arrow) of submandibular gland show strong immunoreactivity for V-ATPase. The reactivity is diffuse in the cytoplasm with a tendency of concentrating to the lumen. The intercalated duct (arrowhead) is weakly stained. A) Paraffin section, and B) cryostat section. C) P-ATPase is present in the salivary ducts. A $\times 50, \mathbf{B} \& \mathbf{C} \times 100$.

Fig. 4. Immunoreactivity for V-ATPase in epithelial cells of various ducts and glands. A) Ducts of esophageal gland, B) pancreatic ducts, C) bronchial epithelial cells, D) colonic gland, and E) gastric pits (E2) and glands (E3), (E1 and E4: the negative controls). All of these epithelial cells are positively stained with a cytoplasmic pattern. A-D $\times 100$, E1-E4 $\times 200$. 


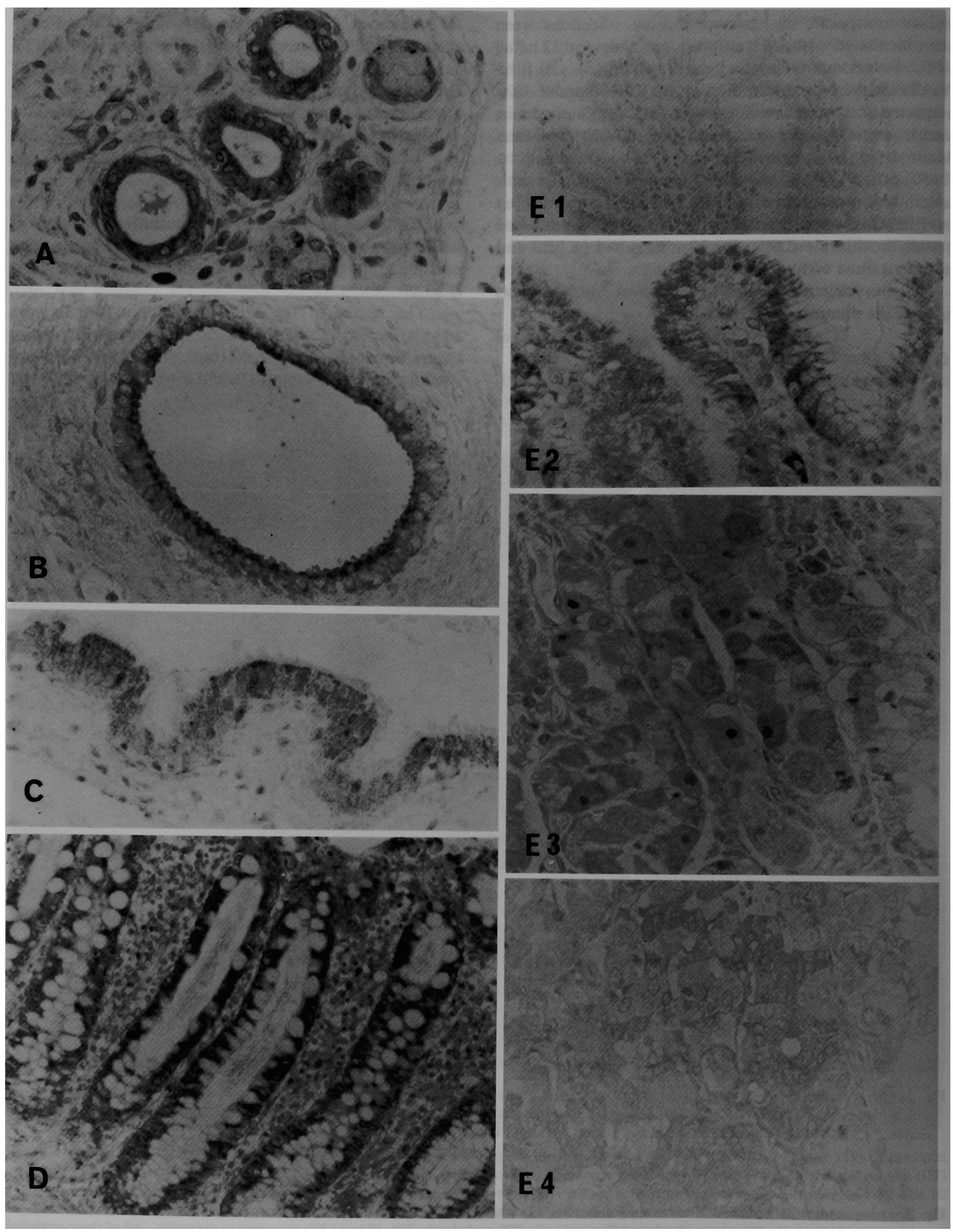

Fig. 4 
same.

1) Epithelial cells of the urinary system including tubules and pelvis (Fig. 2A, B), ducts of salivary gland (Fig. 3A, B), ducts of esophageal gland (Fig. 4A), pancreatic ducts (Fig. 4B), bronchial wall (Fig. 4C), and gastrointestinal tract, such as colon (Fig. 4D) and stomach (Fig. 4E):

Most of these cells were diffusely stained in the cytoplasm to a moderate degree, and epithelial cells of renal tubules and salivary ducts were strongly stained, especially on their apical cytoplasm.

In kidney, V-ATPase was expressed in more variable patterns than in any other tissues. V-ATPase was concentrated in the apical part of intercalated cells (IC) of the distal tubules (DT), and the cortical and inner medullary collecting tubules (CCT and IMCT). It was also localized along the luminal surface of the proximal tubules (PT) with a strong to moderate degree. Furthermore it was diffuse in the cytoplasm with lower density in the rest of epithelial cells including principle cells (PC) of DT and CT. Parts of the collecting tubules were negative for VATPase. The glomerular cells composed of epithelial, endothelial and mesangial cells were almost negatively stained (Fig. 2A).

In salivary gland, epithelial cells of the striated and interlobular ducts were strongly stained in their apical cytoplasm. The intercalated ducts were moderately stained, while the serous and mucous acini were not stained (Fig. 3A). In the cryosections, a more clear tendency of the antigen concentrating to the apical plasma membrane was noticed (Fig. 3B)

In the stomach, epithelial cells of gastric pits were diffusely stained in their cytoplasm (Fig. 4E2). The parietal cells of gastric gland were weakly stained, while the chief cells were negative (Fig. 4E3).

2) Some endocrine cells including pancreatic islet cells (Fig. 5B), endocrine cells in the colon (Fig. 6A), follicular cells of the thyroid gland (Fig. 6B1), most zona reticularis cells of adrenal cortex and some of the adrenal medullary cells (Fig. 6C1):

These cells showed a diffuse cytoplasmic staining in a moderate degree except endocrine cells in the colon and one type of pancreatic islet cells. Both of them were strongly stained with a granular pattern. The intensely stained pancreatic islet cells were found mostly in the peripheral region of islets. In serial sections, further followed by mirror sections for V-ATPase and glucagon (Fig. 5A, B), these V-ATPase-positive cells corresponded to $\alpha$ cells.

3) Cells of a macrophage lineage including alveolar macrophages (Fig. 7A), osteoclasts (Fig. 8A) and dendritic cells of lymph nodes (data not shown):

Alveolar macrophages, which were CD68-positive and cytokeratin-negative were intensely stained for V-ATPase in their cytoplasm in a granular pattern (Fig. 7A-C).

Osteoclasts were diffusely stained in the cytoplasm (Fig. 8B), and some of them presented a concentration in the ruffled border membrane (Fig. 8D, arrowhead). In order to prove that cathepsin D and carbonic anhydrase II exist in osteoclasts where V-ATPase is localized, these three proteins were stained in serial sections (Fig. 8A-C). The results showed that three of them existed in the same osteoclasts. Dendritic cells were moderately stained in a diffuse cytoplasmic pattern (data not shown).

4) Chondrocytes from bronchioles and joints:

They were intensely stained with a diffuse cytoplasmic pattern (Fig. 9A).

5) The other cells:

Moderate staining was noted in squamous epithelial cells of skin (Fig. 9B), nerve cells of Auerbach's myenteric plexus in colon (Fig. 9C), and nerve cells of brain (Fig. 9D). All of these cells showed a diffuse cytoplasmic pattern.

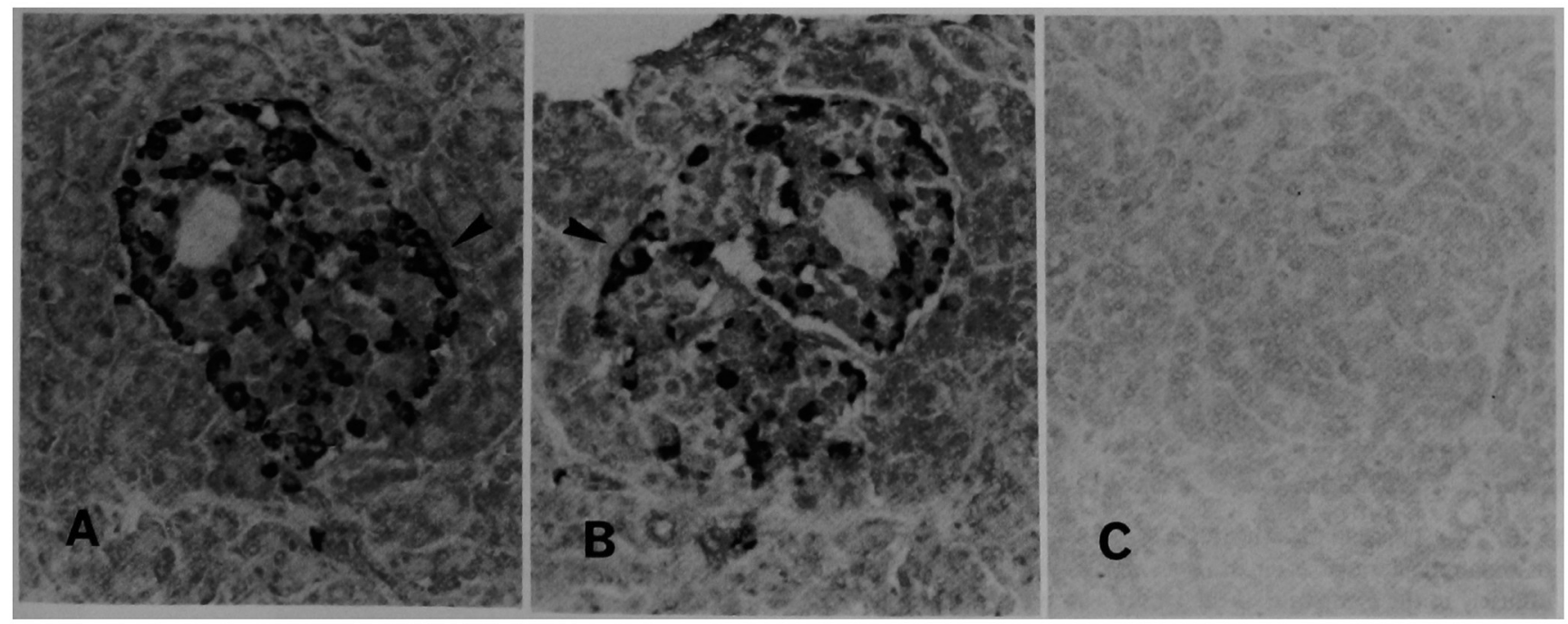

Fig. 5. V-ATPase and glucagon immunostaining of islet cells of pancreas by mirror sections: B) V-ATPase-positive cells in islets correspond to $\mathbf{A})$ the glucagon secreting $\alpha$ cells (arrowhead). C) the negative control. $\times 100$. 


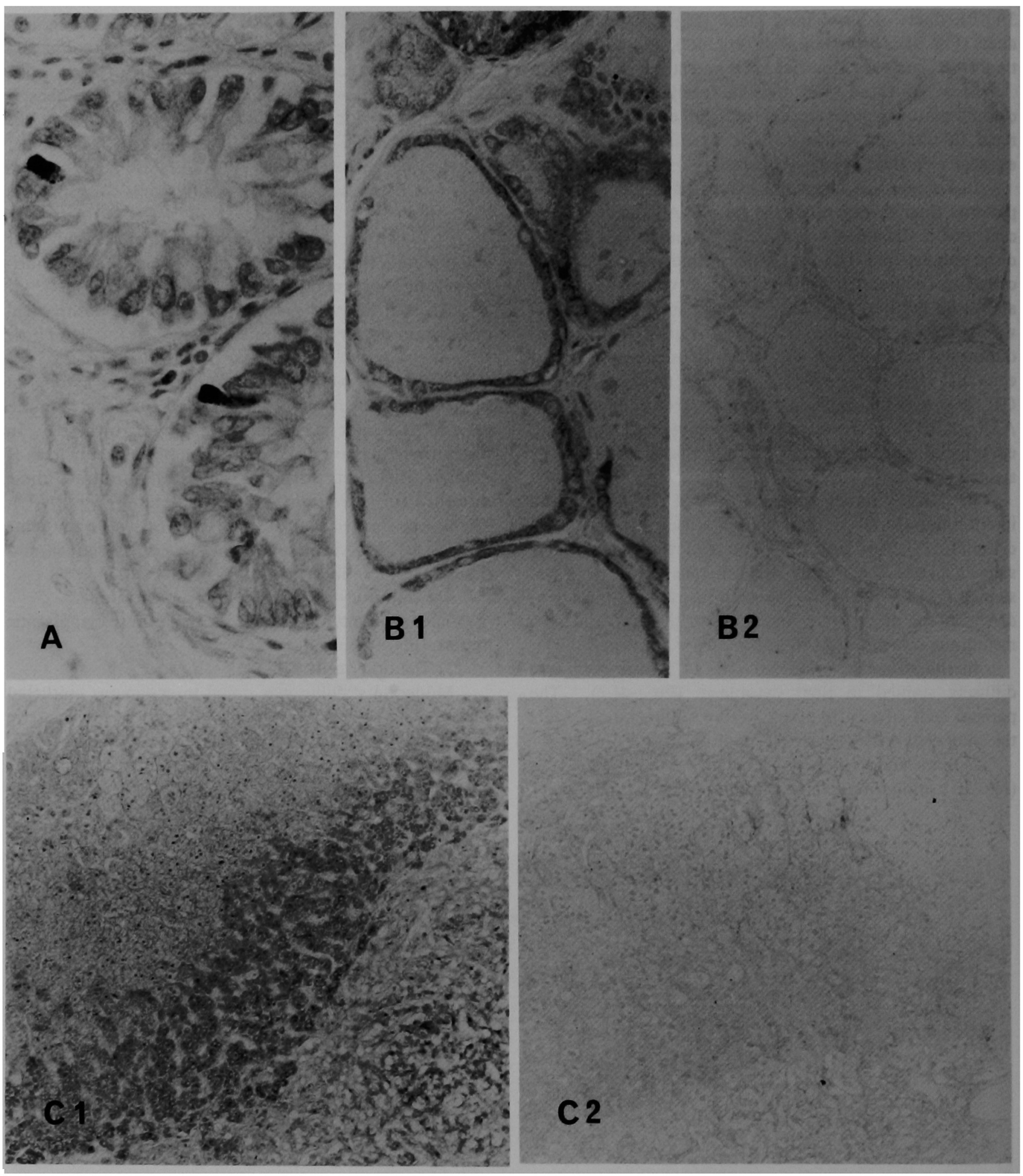

Fig. 6. V-ATPase in the other endocrine cells: A) endocrine cells in colon, B1) thyroid follicular cells (B2: the negative control), and C1) cells of zona reticularis of adrenal cortex (arrow) and parts of the cells of medulla (arrowhead) (C2: the negative control). V-ATPase distributes diffusely in the cytoplasm of these cells with different density. $\mathbf{A} \times 200, \mathbf{B} \times 100, \mathbf{C} \times 25$. 


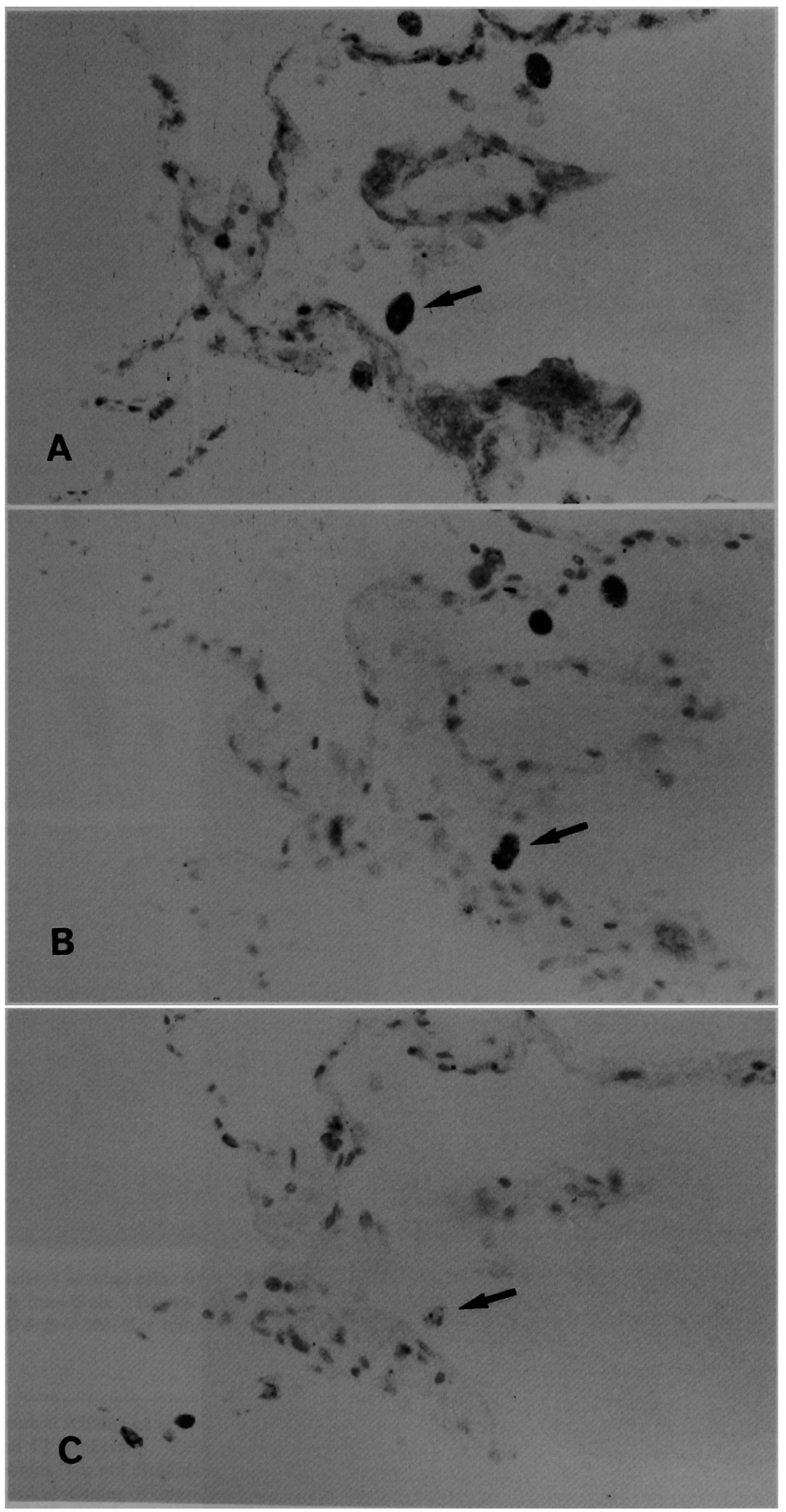

Fig. 7 
Hu et al.
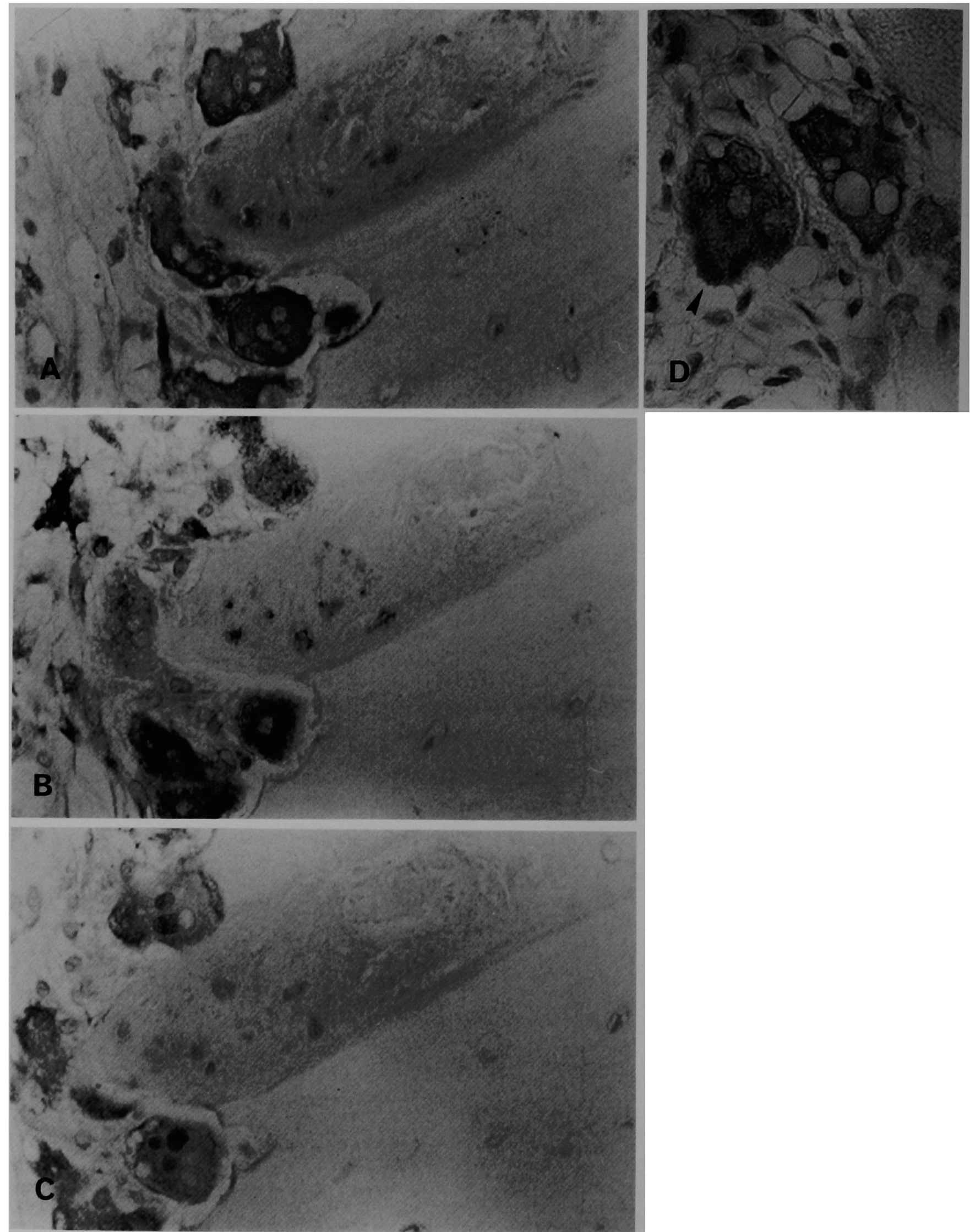

Fig. 8 
All examined tissues demonstrated negative staining after replacing the primary antibodies with normal serum (Figs. 2C, 4E1 4E4, 5C, 6B2, 6C2).

The results from surgical specimens of kidney and salivary gland were substantially the same as those from autopsy. This assured that the results mainly obtained from the observation on autopsy specimens were reliable.

Contrasted to V-ATPase, the expression of P-ATPase was found only in parietal cells of the stomach and epithelial cells of the salivary duct (Fig. 3C). All other tissues demonstrated negative immunoreactivity for $\mathrm{P}$ ATPase in their parenchymal cells.

\section{Discussion}

In this study, the cross reactivity of rabbit antibody against the A subunit of V-ATPase from bovine chromaffin granules in selected human tissues including kidney and salivary gland was confirmed by the immunoblotting. A reactive band was identified at the position of $72 \mathrm{kDa}$, suggesting that a similar molecular structure to that in bovine chromaffin granules exists in human tissues. This result proves that the immunohistochemical stainings were reliable.

According to the localization pattern of V-ATPase in

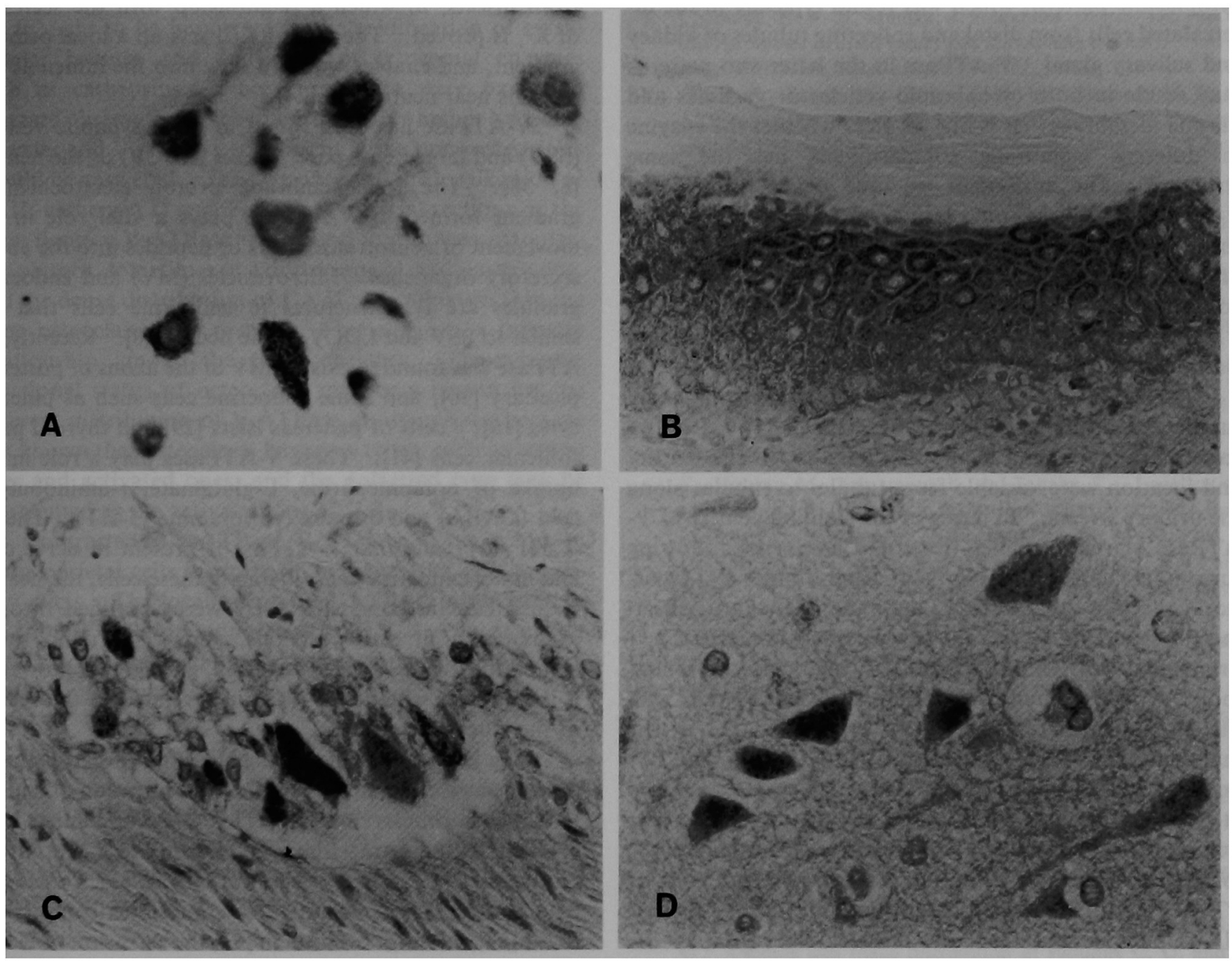

Fig. 9. The immunoreactivity in other cells: A) chondrocytes, B) squamous cells of skin, C) nerve cells from Auerbach's myenteric plexus of colon and D) nerve cells from brain. Besides chondrocytes which are stained strongly, the other three kinds of cells are stained in a weak to moderate degree. A, C \& D $\times 200, \mathbf{B} \times 100$.

Fig. 7. Immunocytochemical staining of macrophages from pulmonary alveoli in serial sections with antibodies against A) subunit A of VATPase, B) CD68, and C) cytokeratin. Cells showing a prominent granular staining with the antibody to subunit A of V-ATPase are CD68-positive macrophages, but not cytokeratin-positive type I pneumocytes (arrow). $\times 100$.

Fig. 8. Immunocytochemical staining of osteoclasts shows mainly diffuse cytoplasmic pattern (A) and partly diffuse apical cytoplasmic pattern (D, arrowhead). Similar diffuse cytoplasmic staining in the same osteoclasts is observed in serial sections using antibodies against $\mathbf{A}$ ) subunit A of V-ATPase, B) carbonic anhydrase II (CAII), and C) cathepsin D. $\times 200$. 
cells, it can be divided into two categories: (1) plasma membrane type in which it functions in proton secretion and subsequently in transport of salt and water, and (2) intracellular membrane type in which it is involved in acidifying the intravesicular compartment of organelles [5, $17,26,32,33]$. The former is limited to parts of cells like epithelial cells of the renal tubules, osteoclasts, macrophages, and so on $[4,12,18,31,42,43]$, while the latter is thought to have an ubiquitous existence. Corresponding to the above classification, in this study, we observed three staining patterns, that is, 1) diffuse cytoplasmic pattern, which was the most common in positively stained cells, 2) diffuse apical cytoplasm pattern, which was typically observed in the proximal tubules of kidney, and 3) polarized cytoplasmic pattern, which was found typically in the intercalated cells from distal and collecting tubules of kidney and salivary gland. V-ATPase in the latter two patterns may reside in both cytoplasmic vesicles or vacuoles and plasma membrane. It is not yet clear whether the enzyme in different membrane compartments has the same structure. The antibodies we used could identify the V-ATPase localized on plasma membrane, as well as those that existed in the intracellular membrane. This finding suggests that V-ATPase from different membrane compartments in most human cells has immunologically a similar structure as reported by Khadouri et al. [22] and Bastani et al. [1].

V-ATPase has been intensively studied in renal tubules. Consistent with previous reports $[1,7,22]$, we found strong staining in the tubules, though the density and location were variable from tubules to tubules along the urinary stream. In terms of the staining density of VATPase of renal tubules, we could assess the following turn: intercalated cells (IC) from distal tubules (DT), cortical collecting tubules (CCT) and inner medullary collecting tubules (IMCT) $>$ cells of proximal tubules (PT) $>$ principle cells (PC) of DT, and CT, and cells of Henles' loop. This distribution tendency corresponds well with the physiological function of $\mathrm{H}^{+}$transport, that is, the main part of $\mathrm{H}^{+}$secretion in kidney is at $\mathrm{CT}$ and then $\mathrm{PT}$, and V-ATPase participates in nearly $1 / 3$ of $\mathrm{H}^{+}$secretion at $\mathrm{PT}$ and almost all at $\mathrm{CT}$, while $\mathrm{Na}^{+}-\mathrm{H}^{+}$exchanger participates in the rest [13]. V-ATPase was all found to be located in the apical cytoplasm of the epithelial cells of PT, DT and CT. This localization pattern suggests that $\mathrm{H}^{+}$is pumped out from the intracellular region to the tubular lumen, but not into the blood, as proved in the previous experimental study [13]. Although Brown et al. $[6,7]$ reported that there was a basolateral gradient in intensity of the enzyme expression in some intercalated cells in cortical CT, we found only the apical staining in DT and CT. Such a diversity may be due to the difference between species and/or antibodies employed, because Brown et al. made their observation in rabbit kidney and used antibodies against the enzyme from bovine kidney microsome.

Both isozymes of V-ATPase were present in human salivary ducts. They were found to be localized densely in cytoplasm near the apical plasma membrane. This finding is consistent with observation by Just and Walz [20] in cockroach and observation by Maddrell and O'Donnell [24] in insect. Such a high expression suggests that VATPase is actively functioning in salivary duct cells. According to the functions of V-ATPase, it can be generally divided into two categories: one is directly regulating the $\mathrm{pH}$ inside organelles, intracellular spaces, and outside of cells by extruding protons across the membrane, and the other is indirectly driving the other ion movements, or regulating further salt transport and water movement by producing an electrical potential difference across the plasma membrane in which they reside. The possible functions of V-ATPase in salivary gland came only from insects, in which a relationship with the secretion of $\mathrm{K}^{+}$is proved. The flux of $\mathrm{KCl}$ sets up a local osmotic gradient, and enables water to flow into the lumen as $\mathrm{pH}$ remains near neutral $[23,24]$.

V-ATPase has been found in small synaptic vesicles (SSV) and large dense core vesicles (LDCV) of the neuron $[8,38]$. The transmembrane proton electrochemical gradient formed by V-ATPase plays a vital role in the movement of neurotransmitters or peptides into the above secretory organelles. Microvesicles (MV) and endocrine granules are the structures in endocrine cells that are similar to SSV and LDCV of the neuron [8]. Recently, VATPase was found to exist in MV of the axons of posterior pituitary [30], and some endocrine cells such as pinealocytes [10], $\beta$ cells of pancreas islets [29] and thyroid parafollicular cells [41]. These V-ATPases play a role in the uptake of norepinephrine, L-glutamate, $\gamma$-aminobutyric acid (GABA) and 5-hydroxytryptamine (5-HT). Thus it is not surprising that V-ATPase is present in nerve cells and many endocrine cells. Among these cells, the heavily stained cells in pancreatic islets were identified through examination of serial sections, and were found to be compatible with $\alpha$ cells secreting glucagon. However, it is not clear whether V-ATPase is related to the release of the glucagon or not.

It is known that mechanical loading of cartilaginous tissue generates an increase in the concentration of cations in the extracellular matrix. This is accompanied by a decrease of the extracellular $\mathrm{pH}$, leading to a drop in the intracellular $\mathrm{pH}$, namely acidification $[11,35]$. Since cartilaginous tissues are exposed to continuous compressing stress [37], causing variation in $\mathrm{pH}$, the extrusion of $\mathrm{H}^{+}$by $\mathrm{H}^{+}$transporters is active, and the transporters themselves should be well developed. We think this is the reason for highly concentrated V-ATPase are found in chondrocytes. Our findings are also consistent with those of Dascalu et al. [11], who proved by chemical analysis that $25 \%$ of $\mathrm{H}^{+}$transportation comes from V-ATPase as compared with other $\mathrm{H}^{+}$transporters.

Cells of a macrophage lineage include macrophages, osteoclasts, and dendritic cells. The immunoreactivity for V-ATPase in these cells was intense or moderate. Although the presence of V-ATPase in lysosomes of mac- 
rophages has been well documented [16], its localization in the plasma membrane still lacks direct evidence. In this study, strong staining with a granular pattern observed in the cytoplasm is the non-polarized pattern. Thus we could not make a judgment whether there was a plasma membrane type of V-ATPase localization in macrophages because it was difficult to distinguish the plasma membrane type from the strongly stained cytoplasmic type at the light microscopic level.

Osteoclasts are multinucleated cells that are responsible for resorption of bone under the condition of acidification of the extracellular lacunae formed between osteoclasts and bone surface, resulting in demineralization, activating proteinases, and further absorption of bone [9, 14]. Proton pump and carbonic anhydrase [21] are thought to be important in the acidification of extracellular lacunae and activation of lysosomal enzymes such as cathepsins. Since these data were based on separate observations, the question as to whether lysosome enzymes and V-ATPase are present in the same osteoclasts should be answered. Thus we observed the localization of CAII, cathepsin D and V-ATPase in serial sections of the same tissue. V-ATPase was found in a diffuse cytoplasmic pattern, sometimes in a diffuse apical cytoplasmic one, and the dense distribution of CA II and cathepsin D in the same osteoclasts was proved. This suggests a intimate relationship among the three enzymes. The variable functional status of osteoclasts may be a reason for the different distribution of V-ATPase in osteoclasts, because it is known that osteoclasts have two types, such as resting ones and activated ones, and the polarized type may be represented as the activated one $[3,36]$.

Contrasted to V-ATPase, P-ATPase is only expressed in the parietal cells in stomach and epithelial cells in salivary ducts. The localization of P-ATPase in the base of the tubular cells of kidney and epithelial cells of rabbit distal colonic gland was reported previously $[40,44]$, but it was not found in this study.

\section{Acknowledgments}

The authors thank Prof. H. Nagura for his valuable advice and editorial assistance, Dr. H. Munakata for his association in immunoblotting analysis, Ms. $\mathrm{H}$. Inoue and Miss C. Kaneko for their technical assistance.

\section{References}

1. Bastani, B., Purcell, H., Hemken, P., Trigg, D. and Gluck, S.: Expression and distribution of renal vacuolar proton-translocating adenosine triphosphstase in response to chronic acid and alkali loads in the rat. J. Clin. Invest. 88; 126-136, 1991.

2. Bernasconi, P., Rausch, T., Struve, I., Morgan, L. and Taiz, L.: An mRNA from human brain encodes an isoform of the B subunit of vacuolar $\mathrm{H}^{+}$-ATPase. J. Biol. Chem. 263; 17428$17431,1990$.

3. Blair, H. C., Teitelbaum, S. L., Ghiselli, R. and Gluck, S.: Osteoclastic bone resorption by polarized vacuolar proton pump. Science 245; 855-857, 1989.

4. Brisseau, G. F., Grinstein, S., Hackam, D. J., Nordstrom, T., Manolson, M. F., Khine, A. A. and Rotstein, O. D.: Interleukin-1 increases vacuolar-type $\mathrm{H}^{+}$-ATPase activity in murine peritoneal macrophages. J. Biol. Chem. 271; 2005-2011, 1996.

5. Brown, D., Cluck, S. and Hartwig, J.: Structure of the novel membrane-coating material in proton secreting epithelial cells and identification as an $\mathrm{H}^{+}$-ATPase. J. Cell. Biol. 105; 1637$1648,1987$.

6. Brown, D., Hirsch, S. and Gluck, S.: An $\mathrm{H}^{+}-$ATPase in opposite plasma membrane domains in kidney epithelial cell subpopulations. Nature 331; 622-624, 1988.

7. Brown, D., Sabolic, I. and Gluck, S.: Polarized targeting of V-ATPase in kidney epithelial cells. J. Exp. Biol. 172; 231243, 1992.

8. Camilli, P. D.: Pathways to regulated exocytosis in neurons. Ann. Rev. Physiol. 52; 625-645, 1990.

9. Chapman, H. A. Jr, Munger, J.S. and Shi, G. P.: The role of thiol proteases in tissue injury and remodeling (review). Am. J. Resp. Crit. Care. Med. 150; S138-S142, 1994.

10. Cidon, S., Tamir, H., Nunez, E. A. and Gershon, M. D. J.: ATP-dependent uptake of 5-hydroxytryptamine by secretory granules isolated from thyroid parafollicular cells. Biol. Chem. 266; 4392-4400, 1991.

11. Dascalu, A., Nevo, Z. and Korenstein, R.: The control of intracellular $\mathrm{pH}$ in cultured avian chondrocytes. J. Physiol. 461; 583-599, 1993.

12. David, P. and Baron, R.: The catalytic circle of the vacuolar $\mathrm{H}^{+}$-ATPase comparison of proton transport in kidney-derived and osteoclast-derived vesicles. J. Biol. Chem. 269; 3015830163, 1994.

13. Ganapathy, V. and Leibach, P. H.: Proton and regulation of biological functions. Kidney Internatl. 40 (suppl 33); S4-S10, 1991.

14. Goto, T., Kiyoshima, T., Moroi, R., Tsukuba, T., Nishimura, Y., Himeno, M., Yamamoto, K. and Tanaka, T.: Localization of cathepsins $\mathrm{B}, \mathrm{D}$, and $\mathrm{L}$ in the rat osteoclast by immuno-light and -electron microscopy. Histochemistry 101; 33-40, 1994.

15. Gottlieb, R. A., Giesing, H. A., Zhu, J. Y., Engler, R. L. and Babior, B. M.: Cell acidification in apoptosis: granulocyte colony-stimulating factor delays programmed cell death in neutrophils by up-regulating the vacuolar $\mathrm{H}^{+}$-ATPase. Proc. Natl. Acad. Sci. USA 92; 5965-5968, 1995.

16. Grinstein, S., Nanda, A., Lukacs, G. and Rostein, O.: VATPase in phagocytotic cells. J. Exp. Biol. 172; 179-192, 1992.

17. Harvey, W. R.: Physiology of V-ATPase. J. Exp. Biol. 172; 117, 1992.

18. Hemken, P., Guo, X. L., Wang, Z. O., Zhang, K. and Gluck, S.: Immunologic evidence that vacuolar $\mathrm{H}^{+}$-ATPase with heterogeneous forms of $\mathrm{Mr}=31,000$ subunit has different membrane distributions in mammalian kidney. J. Biol. Chem. 267; 9948-9957, 1992.

19. Hille, B. V., Vanek, M., Richener, H., Green, J. R. and Bilbe, G.: Cloning and tissue distribution of subunits $C, D$, and $E$ of the human vacuolar $\mathrm{H}^{+}$-ATPase. Biochem. Biophy. Res. Com. 197; 15-21, 1993.

20. Just, F. and Walz, B.: Immunocytochemical localization of $\mathrm{Na}^{+} / \mathrm{K}^{+}$-ATPase and V-ATPase in the salivary glands of the cockroach, periplaneta americana. Cell Tissue Res. 278; 161170, 1994.

21. Karhukorpi, E. K.: Carbonic anhydrase II in rat acid secreting cells: comparison of osteoclasts with gastric parietal cells and kidney intercalated cells. Acta Histochem. 90; 11-12, 1991.

22. Khadouri, C., Cheval, L., Marsy, S., Barlet-Bas, C. and Doucet, A.: Characterization and control of proton-ATPase along the nephron. Kidney Internatl. 40 (suppl 33); S71-S78, 1991. 
23. Klein, U.: The insect V-ATPase, a plasma membrane proton pump energizing secondary active transport: immunological evidence for the occurrence of a V-ATPase in insect ion transporting epithelia. J. Exp. Biol. 172; 345-354, 1992.

24. Maddel, S. H. P. and O'Donnell, M. J.: Insect Malpighian tubules: V-ATPase action in ion and fluid transport. J. Exp. Biol. 172; 417-429, 1992.

25. Montcourrier, P., Mangeat, P. H., Valembois, C., Salazar, G., Sahuquet, A., Duperray, C. and Rochefort, H.: Characterization of very acidic phagosomes in breast cancer cells and their association with invasion. J. Cell Sci. 107; 2381-2391, 1994.

26. Moriyama, Y.: Structure and functions of vacuolar-type $\mathrm{H}^{+}$ATPase from animal cells (review). Biochemistry $65 ; 413-436$, 1993 (in Japanese).

27. Moriyama, Y. and Nelson, N.: The purified ATPase from chromaffin granule membrane is an anion-dependent proton pump. J. Biol. Chem. 262; 9175-9180, 1987.

28. Moriyama, Y. and Nelson, $\mathrm{N}$.: Lysosomal $\mathrm{H}^{+}$-Translocating ATPase has a similar subunit structure to chromaffin granules $\mathrm{H}^{+}$-ATPase complex. Biochem. Biophys. Acta 980; 241-247, 1989.

29. Moriyama, Y. and Yamamoto, A.: Vesicular L-glutamate transporter in microvesicles from bovine pineal glands. J. Biol. Chem. 270; 22314-22320, 1995.

30. Moriyama, Y., Yamamoto, A., Yamada, H., Tashiro, Y., Tomochika, K. I., Takahashi, M., Maeda, M. and Futai, M.: Microvesicles isolated from bovine posterior pituitary accumulate norepinephrine. J. Biol. Chem. 270; 11424-11429, 1995.

31. Nakamura, H., Moriyama, Y., Futai, M. and Ozawa, H.: Immunological localization of vacuolar-type proton ATPase in osteoclast and preosteoclasts. Arch. Histo. Cytol. 57; 535-539, 1994.

32. Nelson, N.: The vacuolar $\mathrm{H}^{+}-$ATPase - one of the most fundamental ion pumps in nature. J. Exp. Biol. 172; 19-27, 1992.

33. Nelson, N.: Structure and functions of V-ATPase in endocytic and secretory organelles. J. Exp. Biol. 172; 149-153, 1992.

34. Perez, L. and Carrasco, L.: Involvement of the vacuolar $\mathrm{H}(+)$-ATPase in animal virus entry. J. Gener. Virol. 75;
2595-2606, 1994.

35. Putnam, R. W. and Grubbs, R. D.: Steady-state pH, buffering power, and effect of $\mathrm{CO} 2$ in a smooth muscle-like cell line. Am. J. Physiol. 258; C461-469, 1990.

36. Sasaki, T., Udagawa, N. and Moriyama, Y.: Expression of vacuolar proton ATPase in osteoclasts during cytodifferentiation. Cell Tissue Res. 278; 265-271, 1994.

37. Stockwell, R. A.: Chondrocyte metabolism. In "Biology of Cartilage Cells", ed. by R. J. Harrison and R. M. H. McMinn, Cambridge University Press, Cambridge, 1979, pp. 67-123.

38. Sudhot, T. C. and Jahn, R.: Proteins of synaptic vesicles involved in exocytosis and membrane recycling. Neuron 6; 665$677,1991$.

39. Supek, F., Supekova, L., Mandiyan, S., Pan, Y. C. and Nelson, N.: A novel accessory subunit for vacuolar $H(+)$-ATPase from chromaffin granules. J. Biol. Chem. 269; 24102-24106, 1994.

40. Takaya, J., Omori, K., Taketani, S., Kobayashi, K. and Tashiro, Y.: Solubilization, purification, and characterization of $\left(\mathrm{H}^{+}, \mathrm{K}^{+}\right)$ATPase from hog gastric microsomes. $J$. Biochem. 102; 903-911, 1987.

41. Thomas-Reetz, A., Hell, J. W., During, M. J., Walch-Solimena, C., Jahn, R. and Camilli, P. D.: A $\gamma$-aminobutyric acid transporter driven by a proton pump is present in synaptic-like microvesicles of pancreatic $\beta$ cells. Proc. Natl. Acad. Sci. USA 90; 5317-5321, 1993.

42. Tomochika, K., Sunoda, S., Kumon, H., Mori, M., Moriyama, Y. and Futai, M.: Vacuolar proton ATPase in mouse bladder epitheliums is responsible for urinary acidification. FEBS Lett. 404; 61-64, 1997.

43. Wieczorek, H.: The insect V-ATPase, a plasma membrane proton pump energing secondary active transport: molecular analysis of electrogenic potassium transport in the tabacco hornworm midgut. J. Exp. Biol. 172; 323-334, 1992.

44. Wingo, C. S., Madsen, K. M., Smojka, A. and Tisher, C. C.: $\mathrm{H}^{+}-\mathrm{K}^{+}$-ATPase acting in distal nephron: stimulation by potassium depletion. Am. J. Physiol. 243; F418-F423, 1987. 